\title{
Practical experiences of instrumentation and monitoring for depillaring
}

\author{
Ashok Kumar, Arun Kumar Singh, Sahendra Ram, Amit Kumar Singh and Rajendra Singh \\ Strata Mechanics Section, \\ CSIR-Central Institute of Mining and Fuel Research, \\ Dhanbad, India \\ ashok.bhu.min09@gmail.com
}

\begin{abstract}
The challenging nature of strata dynamics in and around goaf edge of a depillaring operation warrants continuous vigilance over the dynamics for a safe and efficient working. Depending upon the nature of the working and surrounding rock mass, a variety of geo-technical instruments are, generally, deployed for the vigilance. Selection of positions and installation of these instruments involve good understanding of behavoiur of the associated rock mass, but continuous monitoring of their observations becomes an important issue. In a conventional depillaring working, most of the observations are monitored manually, which may lead to safety threat and unsafe design of the mining structures. Some of the observations of a data-logger based monitoring are proved to be very useful, but the involved financial constraints have restricted its large scale application. Simple incorporation of an electronic continuity circuit in the single point borehole extensometer is known as auto warning tell-tale (AWTT), which has enabled to watch a given value of the roof lowering continuously. This ability of AWTT has proved to be an advantage while depillaring: especially mechanized depillaring. However, it requires a vital input about the rock mass behaviour: the limit of strata deformation to trigger and flashing the alarm light. Explaining the role of design and safety instruments for given conditions of a depillaring panel, this paper provides experience based examples to choose type and positions of the instruments for the monitoring. Briefly discussing the role of combined instrument approach to compensate the error in estimating the rock mass behaviour at the time of instrumentation, the role of continuous monitoring is illustrated with the help of some field measurements in depillaring panels. With the help of a good input of the estimation of strata characteristics in advance, examples of successful use of AWTTs are presented to show its ability to work as a safety instrument. Experiences and measurements found that the AWTT works well under moderate roof strata. Apart from the nature of overlying strata, the field monitoring indicated a need of supervision in observations of this instrument if the working is influenced by barrier effect, leftour pillars/fenders inside the goaf or by a geological structure. Requirement of other supporting instruments are also mentioned on the basis of the noticed problems of this single point measurement below extreme strata conditions (strong and massive or weak and laminated roof strata).
\end{abstract}

Keywords-AWTT; CIA; instrumentation; depillaring; convergence

\section{INTRODUCTION}

An improvement in percentage of extraction during underground mining of coal brings the challenging issues of strata control. Therefore, the depillaring operation of the commonly used bord and pillar (B\&P) method of miningrequires specialised equipment and skilled manpower to address the strata control issues. Safety of the depillaring operation is always a matter of concern because it involves comprehensive roof-pillar interactions and the intensity of the interaction varies at different stages of the depillaring in a panel. The performance of a depillaring operation depends upon the behaviour and response of the rock mass, surrounding the working. It is difficult to predict the behaviour of the rock mass by usual means like manual field monitoring and numerical modelling[1]. Different efforts made by theoretical assumptions[2] and modelling[3] [4] do not generate valuable and reliable results. It happened so because the actual rock mass behaviour is completely different from the usual assumptions. This is the reason why most of the strata based formulations are empirical[5][6]. Here, it is required to have an assessment of performance of different associated mining structures i.e. pillar, roof strata and applied support in the field. Any such performance evaluation in the field involves a number of measurements through underground instrumentation and monitoring [7] [8] [9].

Selection of suitable instruments and observation stations in a depillaring panel depends upon the experience of strata control studies and knowledge of the rock mass properties. Combined Instruments Approach (CIA) is used by CSIRCIMFR [10] during strata control monitoring at different coal mines under competent roof strata. A variety of instruments are utilized for the strata control studies, but there was a lack of an automatic indicator of the pre-set dangerous condition till arrival of the auto warning tell-tale (AWTT). A number of panels in GDK11 Incline and Pinoura mines have been depillared successfully just by the installation of AWTT at suitable locations with a reasonable pre-set of the dangerous level indicator. It has an advantage over the remaining instruments that it constantly keeps watching the set danger level of roof to floor convergence. As soon as this instrument experiences the convergence, more than the pre-set value, it triggers flashing of light. In fact, the flashing of light works well in the dark environment 
of the underground and becomes a good indicator of the roof fall threat. To fix value of the pre-set convergence is, probably, the most important factor for such a continuous (in time) watching instrument and is dependent upon the chosen site conditions. Discussing the underground instrumentation and monitoring issues, this paper presents results of AWTT for an efficient depillaring.

\section{DEPILLARING OPERATION}

Coal mining industry of the country has initiated a number of Continuous Miner (CM) based mechanized depillaring (MD) of standing pillars with encouraging results. Here, the depillaring is being done of the existing square/rectangular pillars by CM. This approach of depillaring created different operational conditions, mainly, due to the following reasons: irregular shape of rib/snook (Fig. 1), straight line of extraction, faster rate of extraction and application of high capacity, pre-tensioned, stiff and resin grouted roof bolts as support system. Geo-technical elements of most of these MD operations are designed by different consultants. Such a design is, generally, site specific and its performance need to be evaluated during the field trail. The performance evaluation requires a number of instruments and, generally, the instruments are made capable to display (tell-tale type) continuous reading. However, it is required to carefully watch these instruments during the depillaring operation. In the case of an AWTT, it is not, generally, required to take readings as it keeps monitoring a pre-set value of the roof convergence. If the convergence crosses the pre-set value then it provides flashing alarming light.

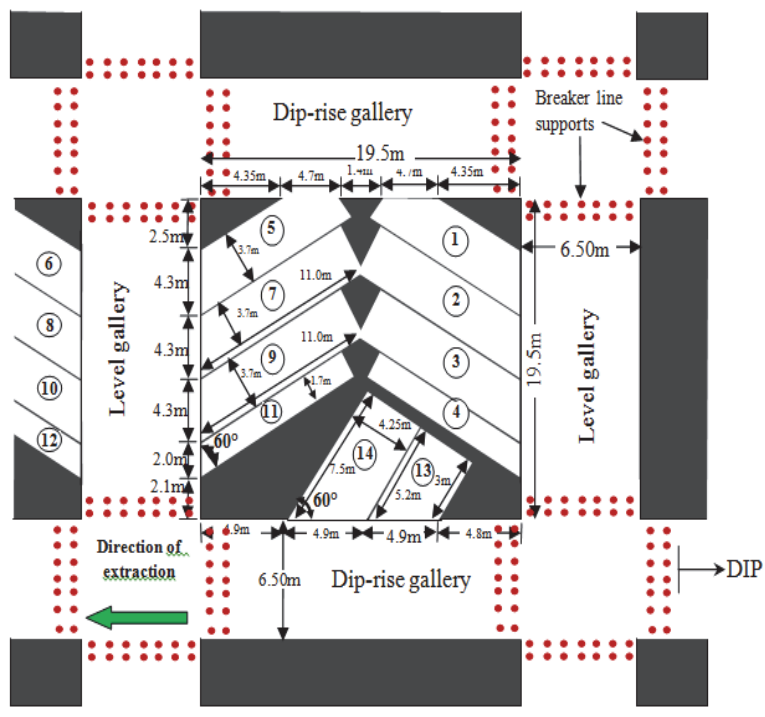

Fig. 1. Manner of pillar extraction in mechanised depillaringpanels of L-1B seam at Pinoura Mine.

A depillaring operation confronts with three different types of natural supports i.e. pillars, fenders/stooks and snook/rib/remnants of a pillar. In a MD operation, pillars are long term stable, fenders remain intact for 10 to 12 hours and remnants of a pillar i.e. rib/snook are stable for around couple of hours only. Installation and monitoring of instruments is difficult in and around a short term stable structures. Generally, the installed instruments are allowed to travel inside the goaf. Here, it is essential to have a remote system of instrument for the observations. The influence of strata dynamics is, relatively, high in and around the goaf edge, so the frequency of observation of the surrounding instruments increases around ribs/snooks.

Generally, the caving of roof strata inside the goaf is preceded by certain amount of roof convergence, which can be easily detected by a telltale. AWTT is a single height type telltale with a simple electrical circuit, which triggers light flashing after crossing the pre-set critical value of the convergence. In fact, the critical pre-set value of the convergence is estimated through experience of previous convergence measurements in the area (Table I). In fact, generally, the experienced low value of the roof to floor convergence causing roof fall is considered as the pre-set critical value. The reference anchor of the AWTT is fixed deep inside the roof strata $(>10 \mathrm{~m})$, which is free from any roof deformation. This combination of large reference height and low trigger value is intended to ensure that the AWTT warning is triggered prior to a major caving event. AWTT gives a pre roof fall warning but the problem with this instrument is that it does not reflect any digital value of the roof convergence.

TABLE I. Vulnerable OBSERVATIONS OF ROOF TO FloOR CONVERGENCE AT DIFFERENT LOCATIONS IN A CM PANEL OF A MINE TO ESTIMATE THE PRE-SET VALUE OF AN AWTT

\begin{tabular}{|c|c|c|c|l|}
\hline Sl. No. & Location & Date & Reading $(\mathbf{m m})$ & \multicolumn{1}{|c|}{ Remarks } \\
\hline 1 & $54 \mathrm{D} / 48 \mathrm{~L}$ & $03 / 05 / 2013$ & 12 & Main fall \\
\hline 2 & $52 \mathrm{D} / 50 \mathrm{~L}$ & $20 / 05 / 2013$ & 10 & Fall took place after $20 \mathrm{hrs}$. \\
\hline 3 & $48 \mathrm{D} / 48 \mathrm{~L}$ & $15 / 06 / 2013$ & 20 & Major fall inside goaf \\
\hline 4 & $48 \mathrm{D} / 50 \mathrm{~L}$ & $15 / 06 / 2013$ & 20 & Fall taken place after $8 \mathrm{hrs}$. \\
\hline 5 & $46 \mathrm{D} / 48 \mathrm{~L}$ & $07 / 01 / 2013$ & - & Fall height $>3 \mathrm{~m}$ \\
\hline 6 & $44 \mathrm{D} / 46 \mathrm{~L}$ & $11 / 07 / 2013$ & 15 & Fall height $>3 \mathrm{~m}$ \\
\hline 7 & $44 \mathrm{D} / 48 \mathrm{~L}$ & $07 / 15 / 2013$ & 25 & Fall height $>3 \mathrm{~m}$ \\
\hline 8 & $42 \mathrm{D} / 48 \mathrm{~L}$ & $23 / 07 / 2013$ & 14 & Fall height $>3 \mathrm{~m}$ \\
\hline
\end{tabular}

\section{CONVERGEnCE MEASURING InSTRUMENTS}

For the strata control measurements a number of electrooptical techniques exist [11] and many are emerging [12]with capabilities to provide remote and precise information about the associated parameters. There are a number of instruments available worldwide to measure the convergence in roof during development of coal pillars and depillaring such as telescopic convergence indicator (TCI), remote convergence indicator (RCI) and borehole extensometer (dual and multi-point). TCI and RCI measure the closeness of two points at a place in the working and goaf respectively (Fig. 2). TCI is manual and RCI is continuous convergence monitoring system but the reading can be known only when it is connected to a readout or data logger.

Extensometers brought a revolution in the measurement of convergence of roof without much effort unlike TCI/RCI. A borehole extensometer with multi-anchor facility is used to locate the parted horizon above the working because the readings of an extensometer give differential movement among the anchors. This instrument is generally fitted in an upward hole drilled from the working horizon. It provides 
valuable information till roof is intact as may be the case of development of a coal seam. This instrument, generally, fails to give important information during depillaring, if installed conventionally in an upward drilled hole. In fact, the deformation/convergence of the overlying strata starts from the immediate roof and then travels inside. Therefore, the mouthpiece (containing sensors) of this instrument gets damaged with the instability in the immediate roof, which ultimately ends the life of the instrument. However, if the multipoint extensometer is installed from surface (shallow depth cover case) or overlying development (multi-seam mining case) through a downward drilled hole, then the instrument provides better information about the bed separation. Here, the roof fall causes loss of the lower anchors only. Overlying anchors and mouthpiece with sensors remain intact even after the roof fall. Multipoint borehole extensometer, placed parallel to a roof bolt in the roof strata, is used to understand the in situ stiffness of a high capacity roof bolt. A suitable placement of different anchors inside the hole, parallel to the grouted roof bolt, demonstrates the capability of the bolt to control the movement of laminated roof strataduring depillaring.

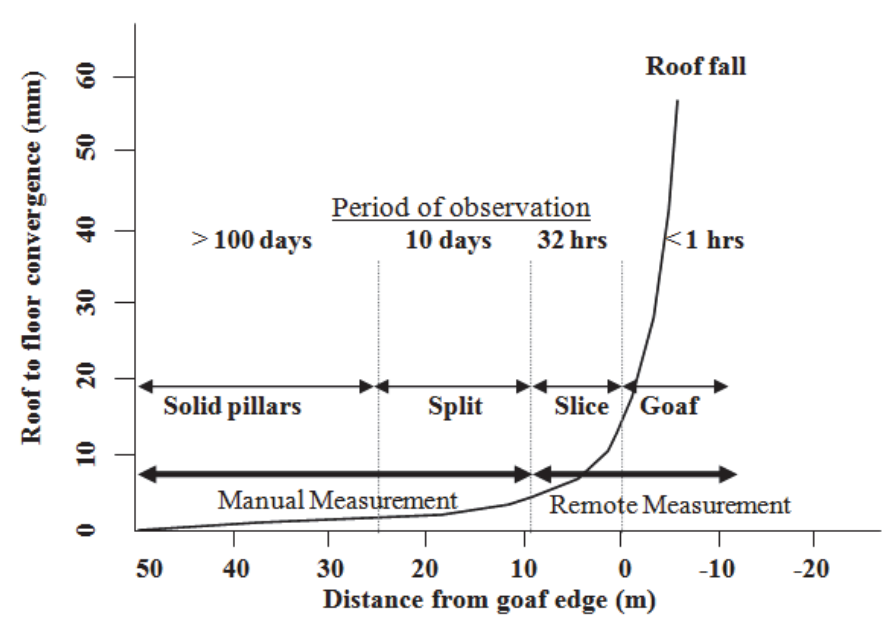

Fig. 2. Observed variation in roof to floor convergence with goaf edge by manual and remote measurements during a conventional depillaring [1].

As per operational conditions, generally, an upward hole is available for such measurement in a MD operation, where single point extensometer becomes an obvious choice. AWTT is a single point extensometer, whose reference anchor is fixed in a horizon, much above the expected parting plane inside the roof strata. The horizon at which AWTT's reference anchor is to be installed and the critical value of the pre-set convergence for triggering the alarm of warning are site dependent.

\section{AWTT}

AWTTs play an important role for safety of the working from strata control point of view during the depillaring operation. Golder Associates' intrinsically safe AWTT (Fig. 3) [13] has been designed to provide a highly visible immediate warning [14] of excessive movement occurring in a rock-bolted tunnel or mine roadway, over and above that provided by the coloured bands on a standard tell-tale. It is based on the premise that goafing events happen after a smaller value of roof convergence, which will be detected by the tell-tale. However, it may not always be possible to record or notice this value of the roof convergence and, therefore, the attached simple electrical device would automatically trigger the alarm. Such an approach is of good importance in a dynamic situation like depillaring, where the workmen and equipment are operating close to a developing goaf. The AWTT [15] does not consume any power prior to being triggered and so can remain in storage or in a quiescent state in the roof for several years before operation of the LEDs. The configuration also allowsthe condition of the unit to be checked easily once installed, by manually pushing the indicator upwards to temporarily trigger the LED. The AWTT has been designed and approved to be intrinsically safe to both IECEx and ATEX standards. The AWTT is currently being used in all mechanized depillaring operations in ECL, SECL, WCL and SCCL. There are two factors which are responsible for the performance of any instrument in underground coal mining which are discussed in subsequent section.

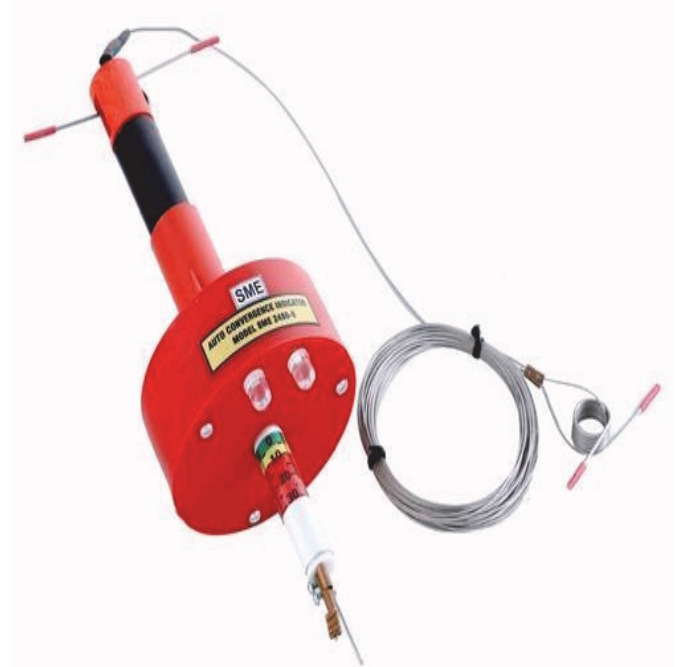

Fig. 3. An Auto warning tell-tale (AWTT) with extension lead and reference anchor.

\section{A. Underground environment}

Heat, humidity, visibility, danger of roof and side falls and space constraint of underground working influence the selection of instrument to be used for monitoring. An environment like surface facilitates a number of available instruments which can provide information continuous in space and time. But, due to unfavourable conditions of an underground mine, only limited instruments have the capability for the monitoring. Generally, mechanical and electro-mechanical types of instruments are deployed for the above discussed monitoring.

Mechanical instruments are non-remote type, where observations are to be taken manually and once the instrumented area becomes inaccessible then scope of study is only left with the electrical/electronic sensor based instruments. But, the sensor based instruments need to be intrinsically safe, portable and robust to face the difficult 
underground working conditions. Data logger/read out unit of these instruments brings a number of safety constraints and can be tackled if data can be transmitted to a remotely located safe place of the readout.AWTT is an electromechanical intrinsically safe instrument which is least affected by environment and continuously monitoring the roof convergence for a pre-fixed critical value. There is no need of attaching data logger/readout with AWTT as the reading are marked on the instrument with color bands and it starts flashing, the moment convergence exceeds the prefixed value.

\section{B. Influence of overlying rock mass}

The performance of underground mining structures is mostly governed bydepositional condition of the site [16]. Underground mines at shallow cover are governed by different rock engineering norms than those for mines at deeper cover. It is worth mentioning here that, generally, the stability of excavations close to surface is mainly controlled by the rock structures while the stability of deeper excavations is more influenced by the properties of intact rock and pre-existing stresses[17]. The nature of rock mass in the overlying roof plays a major role in setting the triggering and flashing limit of AWTT. There is a lack of reported study for fixation of the critical value of the roof to floor convergence. However, CSIR-CIMFR had an opportunity to study roof to floor convergence for the installation of AWTT at some mines of our coalfields. On the basis of these studies at these mines, the values of critical convergence (Table II) are established for the AWTT. Even these values of the convergences for each mine need to be examined regularly to consider the changes in geo-mining conditions.

TABLE II. VALUES OF CRITICAL CONVERGENCE FOR AWTT AT DIFFERENT MINES

\begin{tabular}{|l|l|l|l|l|}
\hline S1. No. & Mine & Method & Roof strata & Triggervalue $(\mathrm{mm})$ \\
\hline 1. & A & Mechanised depillaring & Moderate sandstone & 5 \\
\hline 2. & B & Blasting gallery & Coal & 25 \\
\hline 3. & C & Conventional depillaring & Competent sandstone & 5 \\
\hline 4. & D & Mechanised depillaring & Carbonaceous shale & 10 \\
\hline 5 & E & Mechanised depillaring & Moderate sandstone & 5 \\
\hline
\end{tabular}

Considerable variation is found in the triggering limit of an AWTT and, therefore, a time study of roof fall after the trigger of light flashing helps in ensuring safety of the depillaring area. The depth of reference anchor installation solely depends upon thickness of the overlying likely to be influenced by the width of excavation at the observation point. The triggering limit depends upon the reaction of rock mass after crossing the elastic limit. Coal bears maximum convergence when compared to sandstone. Generally, a small deformation in sandstone roof leads to failure whereas a coal strata withstands, relatively, larger convergence before the fall.

\section{FIELD OBSERVATIONS BY AWTT}

Considering the safety potential of the AWTT, this instrument is installed at every tri and four way junction in a MD panel. For an assessment of the set critical value of theconvergence in the AWTT, time delay in roof fall occurrence around their locations is recorded after flashing of the AWTT. The time interval between start of AWTTs flashing and occurrence of roof fall around the respective instrument's position depends on various factors. These observed factors in a MD panel are: roof blasting inside the goaf, partial extraction of the adjacent pillars, hanging of small area/width of goaf (beyond the position of instrument) after the roof fall, orientation of geological discontinuities, barrier effect and rate of goaf advance.

Although there is a considerable amount of variation in the time interval between start of an AWTT flashing and roof falls at different stages of the depillaring, an attempt is made to analyze these observations as per the position of this instrument in the panels. A histogram of the time interval between the flashing and falls at different locations in a MD panel is given in Fig. 4. This histogram shows a considerable amount of variation in the time interval between start of AWTT flashing and roof falls among different AWTTs installed in the panel. In the beginning, the roof fall was hindered by barrier pillar effect and the straight line of extraction did not provide enough width for a roof fall. However, the width created by one row of pillars generated enough convergence to cross the set limit in the AWTTs. Therefore, if the observations of only first row of pillars are removed then the averge delay time of roof fall after flashing becomes nearly half. Out of 113 observations, the time interval between the flashing and fall at one place in the panel is observed to be 30 minutes only, while others are considerably large.

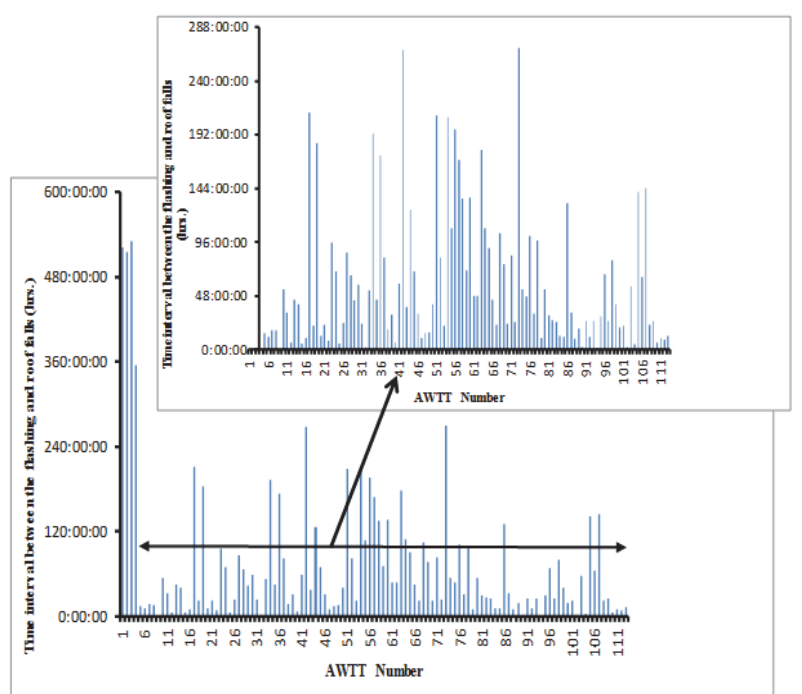

Fig. 4. Histogram of the time interval between the flashing and falls at different instrumented positions in a MD panel.

An attempt is made to categorise these observations as per a set of these instruments, installed in each dip-rise gallery of the panel. This categorisation is, mainly, aimed to visualise the impact of left out fenders/ribs and width of void (along level) over the time interval between start of AWTT flashing and roof falls. For this purpose, an average value of the time interval between start of AWTT flashing and roof falls for all the AWTTs in each dip-rise gallery of 
the panel is calculated. Graphical presentations of this average time interval along different stages (area of extraction) of depillaring are shown in Fig. 5. This shows that the delay in fall after flashing reduces with advance of the depillaring operation. In addition to the barrier pillar effect, the first row of extraction encountered partial extraction of two pillars due to geological structures, which also delayed the caving even after occurrence of the critical convergence at the instrumented positions. Further, there was a problem in full extraction in $4^{\text {th }}, 5^{\text {th }} 6^{\text {th }}$ and $7^{\text {th }}$ rows of pillars due to geological structures, and bigger sizes of ribs were left inside the goaf, which delayed roof fall even after flashing of the AWTTs.

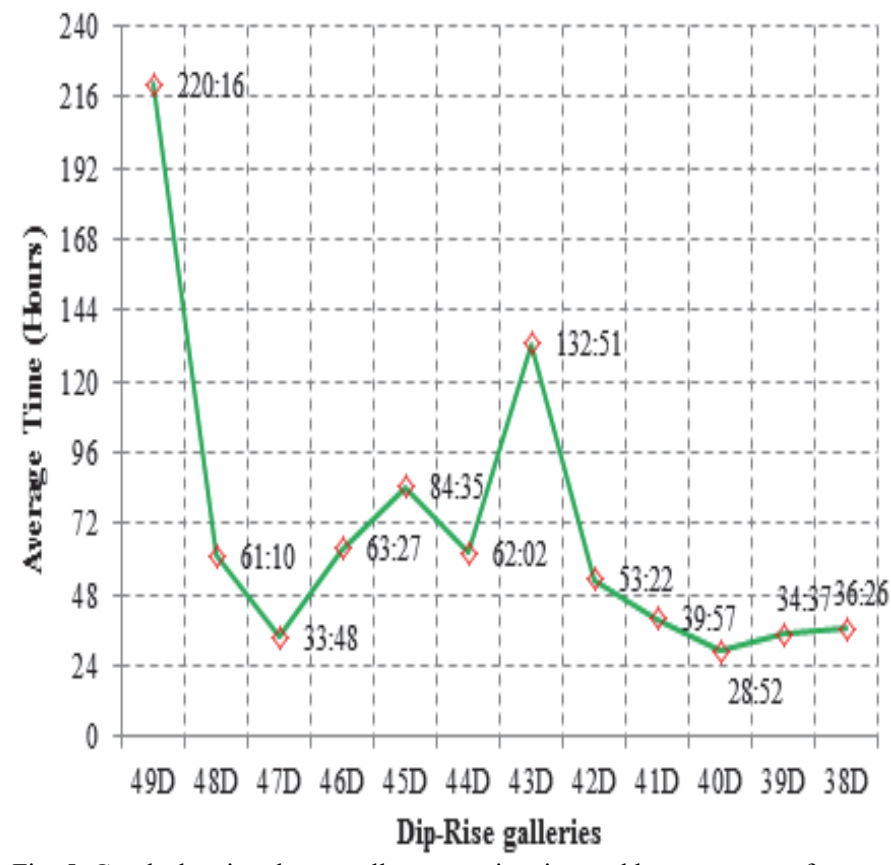

Fig. 5. Graph showing the overall average time interval between start of AWTT flashing and roof fall around their locations.

\section{CONCLUSIONS}

Instrumentation is vital for the safety but it is highly challenging and technical to extract information from the readings of these instruments to project the strata behaviour during an underground coal mining. Simplicity, robustness and ability to constantly watch for a set value of convergence for an alarm have established the faith of coal miners in AWTT, specially, during mechanised depillaring. But installation depth of reference anchor of the AWTT still falls in grey area due to the anisotropic behaviour and nonuniformity of strata conditions at different mines. Presetting of the triggering limit is another important point for AWTT, for which an initial study of the roof rock mass and their convergence is essential. Convergence is not the sole parameter to predict roof fall but most of the mines are using it as a safety tool, where AWTT has to play a significant role. A combination of different geo-technical instruments like stress meters, load cells, Instrumented bolt,extensometer, convergence indicator and AWTT may prove to be a better system for safety and efficiency of the MD.

\section{ACKNOWLEDGMENT}

The authors are obliged to Dr. P. K. Singh, Director, CSIR-CIMFR, for his permission to publish this paper. Mr. Rakesh Kumar of Strata Mechanics Section provided considerable help in field work is really acknowledged. The co-operation provided by the management of different coal companies during the field study is thankfully acknowledged. The views expressed in the paper are those of the authors, and not necessarily of the institute to which they belong.

\section{REFERENCES}

[1] R. Singh, A. K. Singh, P. K. Mandal, M. K. Singh and A. Sinha, "Instrumentation and monitoring of strata movement during underground mining of coal," Minetech, Vol. 25, no.5, pp.12-26, 2004.

[2] J.N.van der Merwe, "Fundamental analysis of the interaction between overburden behaviour and snook stability in coalmines," The Journal of the South African Institute of Mining and Metallurgy, Vol. 105, no. 1, pp. 63-73, 2005.

[3] B. Unverand N. E. Yasitli, "Modelling of strata movement with a special reference to caving mechanism in thick seam coal mining,'Int. J Coal Geol., Vol. 66, no.4, pp. 227-252, 2006.

[4] A.K. Singh, R. Singh, J. Maiti, P.K. Mandal, R. Kumar, “Assessment of mining induced stress development over coal pillars during depillaring," International Journal of Rock Mechanics and Mining Sciences, Vol. 48, no. 5, pp. 805-818, 2011 a.

[5] V. Venkateswarlu, A.K. Ghose and N.M. Raju,"Rock mass classification for design of roof support-a statistical evaluation of parameters," Min. Sc. Tech. Vol. 8,pp. 97-107, 1989.

[6] P. R. Sheorey, "Pillar strength considering in situ stresses," Information Circular (IC), 9315, United States Department of the Interior, Bureau of Mines, pp. 122-127, 1992.

[7] B.Shen, A.King andH.Guo,"Displacement, stress and seismicity in roadway roofs during mining-induced failure,'International Journal of Rock Mechanics and Mining Sciences, Vol.; 45, no. 5,pp. 672-688, 2008.

[8] B. K. Hebblewhite, and T. Lu, "Geo-mechanical behaviour of laminated, weak coal mine roof strata and the implications for a ground reinforcement strategy," International Journal of Rock mechanics and Mining Sciences, Vol. 41, pp. 147-157, 2004.

[9] P. F. R. Altounyan, N. D. Bigby, K. G. Hurt and H.V. Peake, "Instrumentation and procedures for routine monitoring of reinforced mine roadways to prevent falls of ground," $27^{\text {th }}$ International Conference of Safety in Mines Research Institute, Editors: B. B. Dhar and B. C. Bhowmick, pp. 759-766, New Delhi, India, 1997.

[10] R. Singh, A. K. Singh,J. Maiti, P. K. Mandal, Rashmi Singh and R. Kumar, "An observational approach for assessment of dynamic loading during underground coal pillar extraction," International Journal of Rock Mechanics and Mining Sciences, Vol.48, no. 5, pp. 794-804, 2011 b.

[11] E. Hoek and E. T.Brown, "Underground excavations in rock," Institute of Mining and Metallurgy, pp. 527, London, 1980,

[12] T. A. Clarke,"The use of optical triangulation for high speed acquisition of cross section or profile of structures," Photogrammetric Record, Vol. 13, no.76, pp. 523-532, 1990.

[13] www.golder.com/instrumentation,"Instrumentation - Information Sheet,Auto-warning tell-tale: Single Height Version-ModelTTAW1," uk/ire 327-s (07-13) v2 Engineering earth's development, preserving earth's integrity.

[14] RMT Report, "Data analysis of installed RMT instrumentation in Zero Seam, Panel C, Anjan Hill, Chirimiri Colliery, SECL, 38 pages, 2003. 
[15] J. P. Goenka and V. Jain, "Strata monitoring by tell-tale, description, application and suggestions,"'Reprint of the Articles read at MGMI Paper meeting, 28 July 2012, Saltlake, Head Quarter, Kolkata, India.

[16] B. G. D. Smart and N. I. Aziz,"The influence of caving mechanism on powered support rating,"The Australian IMM Bulletin and proceedings, Vol. 294, no.4, pp.77-84, 1989.

[17] R. Singh and T. N. Singh, "Wide stall mining for optimal recovery of coal from a thick seam under surface features," International Journal of Rock Mechanics and Mining Sciences, Vol. 36, no. 2, pp. 155-168, 1999. 